\title{
Complete versus Staged Revascularization in Patients with Non-ST Segment Elevation Acute Coronary Syndrome (NSTE-ACS) and Multivessel Disease
}

\author{
Mohammed H. Kabil, Ahmed Bendary, Mohamed A. Salem, Khaled E. El Rabbat
}

\begin{abstract}
Department of cardiology, Benha faculty of medicine, Benha University, Egypt.
\end{abstract}

Correspondence to: Mohammed H. Kabil, Department of cardiology, Benha faculty of medicine, Benha University, Egypt.

Email:

mohammed_hamza_5@hotma il. com

Received: 17 September 2020 Accepted: 15 November 2020

\begin{abstract}
:
Aim of the work: A study to compare 6-month clinical outcome of immediate multivessel PCI versus staged PCI in patients with NSTEACS and multi-vessel disease. Patients and methods: Randomized study included 100 patients with NSTE-ACS who were admitted to the CCU at Benha university hospital divided into 2 groups; group I \& group II. Results: The in-hospital outcome in group I was $10 \%$ and in group II was $14 \%, 2 \%$ of the cases with in-hospital cardiogenic shock in group I and $2 \%$ of the cases in group II, $4 \%$ of the cases with in-hospital heart failure in group I and $6 \%$ of the cases in group II, In-hospital CIN occurred in $4 \%$ of the cases in group I and in $8 \%$ of the cases in group II, and this differences did not show any statistical significance $(\mathrm{P}>0.05)$. The 6-months outcome was assessed in $7 \%$ of all cases divided into $8 \%$ in group I and 6\% in group II while 6-months recurrence of angina was detected in $3 \%$ of all cases divided into $4 \%$ in group I and $2 \%$ of the case in group II. 6-months heart failure was found in $4 \%$ of the whole cases divided into 2 cases in each group but 6-months all-cause mortality. 6-months urgent TVR and 6-months non-fatal MI were not
\end{abstract} found in any cases in this study. All of those outcomes did not show any statistical significance $(\mathrm{P}>0.05)$. Conclusion: Immediate complete revascularization resulted in similar rates of in-hospital and 6-month outcomes compared to staged revascularization.

Key words: NSTEMI, Multivessel disease, Complete Vs staged revascularization. 


\section{Introduction}

Atherosclerotic coronary artery disease (CAD) is a diffuse process, often patients presenting with unstable angina or non-ST-segment elevation myocardial infarction (NSTEMI) have multiple lesions that may be suitable for percutaneous coronary intervention (PCI) (1).

In the era of contemporary medical therapy, it is not clear whether intervening on stable chronic non-culprit lesions in patients with NSTE-ACS can prevent major adverse cardiovascular events. In addition, multivessel stenting in this setting could potentially be associated with greater dye load and periprocedural myocardial infarction (MI) secondary to side branch closure and distal embolization (2). Multivessel disease (MVD) is noted in about half of patients with NSTE-ACS (3).

It is associated with increased mortality after MI (4). In the Framingham and Fast Revascularization During Instability in Coronary Artery Disease (FRISC) II trial, one of the landmark studies that changed the NSTEMI strategy toward an early invasive strategy, revascularization was recommended in any artery with $>70 \%$ stenosis (5). In contrast to STEMI, determining the culprit artery in NSTEMI is not always feasible in all patients. A coronary lesion should be considered culprit if it fulfills at least two of the following criteria: intraluminal filing defect, plaque ulceration, plaque irregularity, dissection or impaired flow. (6), (7) \& (8).

However, it is not clear whether multivessel percutaneous coronary intervention $(\mathrm{PCl})$ beyond the culprit lesion in patients with NSTE-ACS and MVD can improve long-term prognosis. Few studies have compared longterm outcome of multivessel revascularization (MVR) and single-vessel revascularization (SVR) in patients with NSTE-ACS and MVD undergoing PCI (9). However, one of the major limitations of such studies is that differences in endpoints were largely driven by higher rates of repeat revascularization in culprit-only arms which could be expected due to lack of complete revascularization. Moreover, there are no RCT that has compared simultaneous versus staged revascularization, in patients with NSTEMI-ACS. In view of these data, current guidelines have been non-decisive with regards to the ideal treatment strategy for those patients (9).

Therefore, we thought it may be of considerable interest to compare short term clinical outcome of simultaneous multivessel PCI during index procedure versus staged PCI 
in patients presented with NSTE-ACS who have MVD.

\section{Patients and methods}

Study design: This prospective randomized study included 100 patients with NSTE-ACS who were admitted to coronary care unit (CCU) at Benha university Hospital, the study was done during the period from April 2018 to April 2019. The study aimed to compare 6month clinical outcomes of complete simultaneous PCI versus staged PCI in patients with NSTE-ACS and multivessel disease. All patients signed an informed consent and the study was approved by local ethics committee.

Key inclusion criteria: Patients with NSTEACS who have multi-vessel CAD with $\geq 70 \%$ diameter stenosis estimated visually or using quantitative coronary angiography (QCA).

Key exclusion criteria: Patients with prior coronary bypass grafts, patients with chronic total occlusions, Acute ST segment elevation MI (STEMI), uncertain culprit lesions. left main disease, patients with conditions mandating immediate complete revascularization as cardiogenic shock of electrical instability, recent stroke, patients with contraindications to dual antiplatelet therapy or associated co morbidities (liver failure, renal failure, and malignancy) that may limit life expectance to less than 6 months.

\section{Study protocol and methods}

\section{* Baseline evaluation:}

All patients will be reviewed for: medical history, demographic data (age, sex), risk factors for CAD (diabetes, hypertension, smoking, dyslipidemia)., history of previous coronary interventions, heart failure, cardiac medications, comorbidities. Twelve leads Surface ECG immediately on admission and every 6 hours during first 24 hours, and once daily until discharge for assessment of ST-T wave changes and risk stratification of NSTEACS. Cardiac biomarkers: (Cardiac Troponin $\mathrm{T}$ or I \& $\mathrm{CK}-\mathrm{MB}$ at baseline and 6 hours later). Trans-Thoracic Echo Doppler: Transthoracic echocardiography was performed for all patients before coronary catheterization, and whenever indicated. We used the Hewlett Packard Sonos 5500®, equipped with phase array probe of 2.5-3.5 MHz. All patients were studied with M-mode, two-dimensional echo to assess LV systolic function (ejection fraction) using Biplane Simpson method (Apical 4- chamber \&apical 2-chamber) \& to assess presence of RWMA for localization of coronary lesions if possible.

\section{Coronary angiography and PCI:}

- All patients received aspirin (300 mg loading then $75 \mathrm{mg}$ daily), clopidogrel (300 mg loading then $150 \mathrm{mg} /$ day maintenance dose 
for one week then $75 \mathrm{mg}$ / day for one year). The technique was proceeded through retrograde transfemoral arterial approach. A 6 Fr femoral arterial sheath was inserted; Unfractionated heparin (UFH) $(70 \mathrm{u} / \mathrm{kg})$ bolus dose will be injected after sheath insertion. Coronary angiography will be done. Standard coronary angiographic views were obtained to detect the culprit vessel, XB guiding catheters will be used for left coronary lesions and JR catheters for RCA lesions. The culprit lesion is detected if it fulfills at least two of the following criteria: intraluminal filing defect, plaque ulceration, plaque irregularity, dissection or impaired flow. (6)\&(7). Glycoprotein inhibitors were used in lesions with heavy thrombus burden and or impaired TIMI flow after PCI (on discretion of the operator). The operator determined the size and length of the stent, the sheath will be removed 6 hours later from the end of PCI and compression will be done manually. All patients received drug eluting stents either by direct stenting or pre-dilatation technique. The procedure is considered successful when the coronary stenotic lesions managed using stents without a residual stenosis (less than 10\%), TIMI III flow and without procedure related complications (no-reflow, dissection and perforation).

Study protocol: Patients were randomized into 2 groups according to PCI strategy: a) Group I: was subjected to PCI of the culprit lesion only with staged PCI to nonculprit lesions within 2 weeks.

b) Group II: was subjected to PCI of all diseased vessels eligible for PCI (total immediate revascularization).

Study end points: Six-month composite endpoint all-cause mortality, myocardial infarction, need for urgent target vessel revascularization, recurrence of angina symptoms, and heart failure.

\section{Results}

\section{1- Baseline characteristics:}

In this study, 100 patients were included, $56 \%$ males and $44 \%$ females, their average age was 60 years \pm 7 years as Standard deviation. The medical history of those cases was documented and it showed; $82 \%$ were diabetic, while $85 \%$ of the cases were hypertensive, $69 \%$ had a previous history of ischemic heart diseases while $16 \%$ had a history of premature coronary artery diseases and 25\% had previous PCI. $50 \%$ of the patients were smokers, $89 \%$ had Dyslipidemia and $50 \%$ were obese.

Troponin was measured in the all cases and it was positive in the all included cases.

Cases were divided into 2 groups, each group included 50 cases, the average age of group 1 
was 60 years \pm 7 while the group 2 was $61 \pm 7$, and the age difference did not show any statistical significance among both groups $(\mathrm{p}>0.05)$.

In group $1,56 \%$ of the cases were males and $44 \%$ were females also in group 2 there $56 \%$ of the cases were males and $44 \%$ were females, and this gender difference did not show any statistical significance among both groups $(\mathrm{p}>0.05)$.

In group I, $78 \%$ of the cases were diabetic while $80 \%$ were hypertensive , $86 \%$ had

\section{2- Procedural details:}

The average total ischemic time among the 100 cases was 226 minutes \pm 57 standard deviation (SD), the average door to balloon time was 52 hours \pm 7 hours SD, the average time for the whole procedure was 58 minutes and SD was 19.

The average contrast volume used was $337 \mathrm{ml}$ \pm SD 108 , there were two vessels affected in $61 \%$ of the cases and 3 vessels in $39 \%$ of the cases. The Thrombolysis In Myocardial Infarction (TIMI) flow was assessed before and after PCI, $1 \%$ of the cases showed grade $0,33 \%$ of the patients showed grade I, 35\% were grade II and $31 \%$ were grade III before PCI while after PCI there were no cases at grade $0,6 \%$ of the cases were grade I, $1 \%$ was grade II and 93\% were grade III. dyslipidemia, $16 \%$ had history of premature CAD, 70\% had history of ischemic heart disease and 26\% had history previous PCI, in this group $48 \%$ were smokers and 52\% were obese, while in group II $86 \%$ were diabetic, 90\% were hypertensive, $92 \%$ had dyslipidemia, $16 \%$ had history of premature CAD, 68\% had history of ischemic heart disease and $48 \%$ had previous PCI, also in group II $52 \%$ of the patients were smokers and $48 \%$ were obese. All those factors did not show any statistically significance among the both groups ( $p>0.05)$. (Table 1).

The average number of used stents were $3 \pm$ SD 1 with average length $94 \pm$ SD 31, the Drug Eluting Stent (DES) type was used in the all cases of this study and the type of the used PTCA wire was floppy in the all cases of that study. Pre-dilatation was done to the all cases $(100 \%)$ and intra-procedural complications happened at $5 \%$ of the cases only and it was dissection, GP IIb/IIIa was given in 6\% cases.

The total ischemic time in group I was 265 minutes \pm 50 and 197 minutes \pm 48 in group II, and this difference showed statistical significance among our results $(\mathrm{p}<0.05)$. the door to balloon time was about 52 minutes \pm 7 in group I and 51 minutes \pm 7 in group II, but this did not show any statistical significance in this study. 
The average total procedure time was 46 mins \pm 9 in group I and 71 mins \pm 19 in group II, the contrast volume used in group I was average $437 \mathrm{ml} \pm 47$ and $238 \mathrm{ml} \pm 32$ in group II, both procedure time and contrast volume had shown statistical significance among both groups $(\mathrm{p}<0.05)$.

The TIMI flow before PCI in group I was grade Zero in $2 \%$ of the cases, Grade I in $46 \%$ of the cases, Grade II in 34\% of the cases and Grade III in $18 \%$ cases while in group II there were no grade Zero, Grade I in $20 \%$ of the cases, Grade II in $36 \%$ of the cases and Grade III in $44 \%$ of the cases, and this difference showed statistical significance among both groups $(\mathrm{P}<0.05)$.

The TIMI flow after PCI in group I was grade Zero in no cases, Grade I in $6 \%$ of the cases, Grade II in $2 \%$ of the cases and Grade III in $92 \%$ of the cases while in group II there were no grade Zero, Grade I in $6 \%$ of the cases and Grade III in $94 \%$ of the cases, and this difference did not showed any statistical significance among both groups $(\mathrm{P}>0.05)$.

The number of stents used in Group I was two stents in $20 \%$ of the cases, 3 stents in $42 \%$ of the cases and four stents in $38 \%$ of the cases, while in group II two stents were used in $46 \%$ of the cases, 3 stents in $38 \%$ of the cases and four stents in $16 \%$ of the cases, this difference in the both groups showed statistical significance among both groups $(\mathrm{P}<0.05)$.

GP IIb/IIIa was used in $6 \%$ cases in each group and this did not show any statistical significance among both groups.

Intraprocedural complications as dissection was found in $6 \%$ of the cases in group I and in $4 \%$ of the cases in group II and this did not show any statistical significance among both groups in that study (Figure 1)

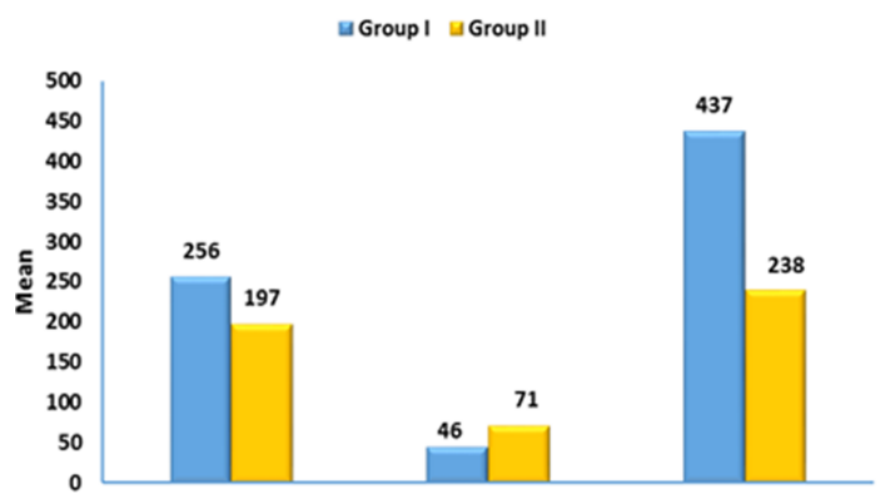

Figure 1: Intraprocedural details differences between group I \& group II regarding total ischemic (min), total .(procedure time (min) \& total contrast volume $(\mathrm{ml})$ 


\section{3- In-hospital outcome:}

The In-hospital outcome in $12 \%$ of the cases undergoing this study was In-hospital mortality in $1 \%$ of the cases only, In-hospital cardiogenic shock in $2 \%$ of the cases, Inhospital heart failure in $5 \%$ of the cases, Inhospital CIN in $4 \%$ of the cases and there was no In-hospital major bleeding among the cases. The In-hospital outcome in group I was
$10 \%$ and in group II was $14 \%, 2 \%$ of the cases with In-hospital cardiogenic shock in group I and 2\% of the cases in group II, $4 \%$ of the cases with In-hospital heart failure in group I and $6 \%$ of the cases in group II, Inhospital CIN occurred in $4 \%$ of the cases in group I and in $8 \%$ of the cases in group II, and this differences did not show any statistical significance in this study $(\mathrm{P}>0.05)$ (Figure 2).

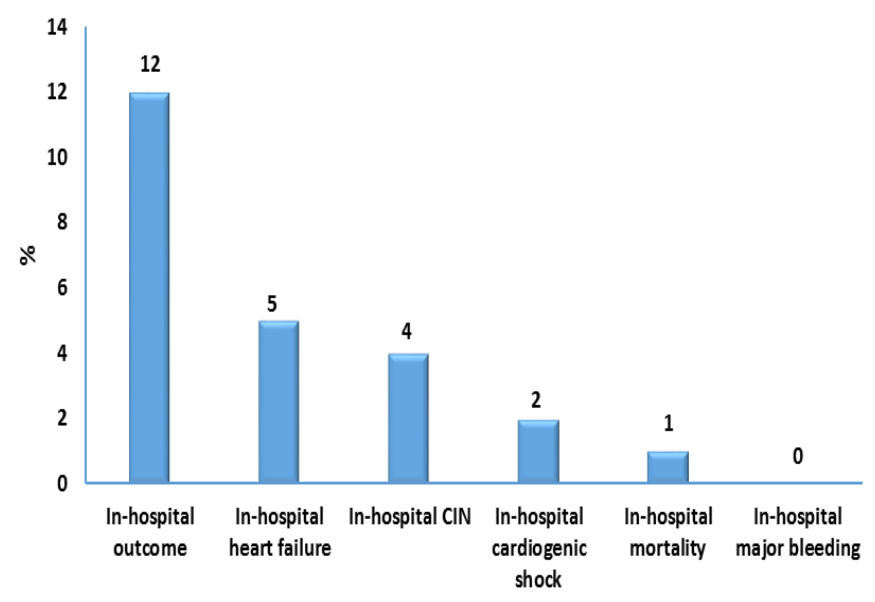

Figure 2: In-hospital outcome in group I and group II

\section{4- 6-months outcome:}

The average time of delaying to $2^{\text {nd }} \mathrm{PCI}$ was 12 days with SD of 3, the cases with In hospital setting of staged procedure were $32 \%$ and the cases with after discharge setting of staged procedure were $68 \%$. The 6 months outcome was assessed in $7 \%$ of all cases divided into $8 \%$ in group I ( 4 cases) and $6 \%$ in group II (3 cases) while 6 months recurrence of angina was detected in $3 \%$ of all cases divided into $4 \%$ in group I ( 2 cases) and $2 \%$ of the case in group II ( 1 case), 6-mo Heart failure was found in $4 \%$ of the whole cases divided into two cases in each group but 6-mo All-cause mortality, 6-mo Urgent TVR and 6-mo Non-fatal MI were not found in any 
cases in this study. All of those outcomes did study $(\mathrm{P}>0.05)$ (Table 2).

not show any statistical significance in this

Table (1): Baseline characteristics difference between group I \& group II.

\begin{tabular}{|c|c|c|c|c|c|}
\hline & & & $\begin{array}{l}\text { Group I } \\
(\mathbf{n}=\mathbf{5 0})\end{array}$ & $\begin{array}{l}\text { Group II } \\
(\mathbf{n}=\mathbf{5 0})\end{array}$ & $P$ value \\
\hline Age (years) & \multicolumn{2}{|c|}{ Mean \pm SD } & $60 \pm 7$ & $61 \pm 7$ & 0.657 \\
\hline \multirow[t]{2}{*}{ Gender } & \multicolumn{2}{|c|}{ Males } & $28(56.0)$ & $28(56.0)$ & 1.0 \\
\hline & \multicolumn{2}{|c|}{ Females } & $22(44.0)$ & $22(44.0)$ & \\
\hline DM & Yes & n $(\%)$ & $39(78.0)$ & $43(86.0)$ & 0.298 \\
\hline HTN & Yes & $\mathbf{n}(\%)$ & $40(80.0)$ & $45(90.0)$ & 0.161 \\
\hline Smoking & Yes & n $(\%)$ & $24(48.0)$ & $26(52.0)$ & 0.689 \\
\hline Dyslipidemia & Yes & n $(\%)$ & $43(86.0)$ & $46(92.0)$ & 0.338 \\
\hline Obesity & Yes & n $(\%)$ & $26(52.0)$ & $24(48.0)$ & 0.689 \\
\hline FH of premature CAD & Yes & n $(\%)$ & $8(16.0)$ & $8(16.0)$ & 1.0 \\
\hline PH of IHD & Yes & $\mathbf{n}(\%)$ & $35(70.0)$ & $34(68.0)$ & 0.829 \\
\hline Prior PCI & Yes & n $(\%)$ & $13(26.0)$ & $12(24.0)$ & 0.817 \\
\hline Troponin & Posit & ve $n(\%)$ & $50(100.0)$ & $50(100.0)$ & NA \\
\hline
\end{tabular}

Independent $t$ test was used for numerical data. Categorical data was compared using Chi-square test.

Table (2): 6-month outcome in group I \& group II

\begin{tabular}{llllll}
\hline & \multicolumn{2}{l}{ Group I } & \multicolumn{2}{c}{ Group II } \\
& N & \% & N & \% & P value \\
\hline 6-mo outcome & 4 & 8.0 & 3 & 6.0 & 1.0 \\
6-mo All-cause mortality & 0 & 0.0 & 0 & 0.0 & NA \\
6-mo Heart failure & 2 & 4.0 & 2 & 4.0 & 1.0 \\
6-mo Urgent TVR & 0 & 0.0 & 0 & 0.0 & NA \\
6-mo Recurrence of angina & 2 & 4.0 & 1 & 2.0 & 1.0 \\
6-mo Non-fatal MI & 0 & 0.0 & 0 & 0.0 & NA \\
\hline
\end{tabular}

Fisher's exact test.

\section{Discussion}

A large body of accumulating data exists in STEMI supporting the role of complete revascularization in patients with MVD undergoing primary PCI. Rigorously performed randomized clinical trials have shown substantial benefit from complete revascularization (10),(11),(12), which have necessitated changes in recent guidelines (13). 
However, whether the results of the PRAMI (Preventive Angioplasty in Myocardial Infarction) (11), CvLPRIT (Complete Versus Lesion Only Primary PCI) (11), and DANAMI-3-PRIMULTI (Primary PCI in Patients With ST-Elevation Myocardial Infarction and Multivessel Disease: Treatment of Culprit Lesion Only or Complete Revascularization) (12) trials can be extrapolated to NSTEMI is unclear (14).

Consistent with the DANAMI-3-PRIMULTI trial (12), some investigators are of the opinion that a physiological assessment-guided revascularization approach would improve outcomes in patients with MVD undergoing PCI. In the FAME (Fractional Flow Reserve versus Angiography for Multivessel Evaluation) study, PCI guided by fractional flow reserve in patients with multivessel CAD demonstrated reduction in death or MI at 2 years when compared with standard angiography-guided PCI (15).

This study was conducted at Benha University Hospitals aiming to compare 6-month clinical outcome of complete simultaneous PCI versus staged PCI in patients with NSTE-ACS and multivessel disease.

The study included a total of 100 cases who were randomized into two groups; group I included 50 cases who underwent PCI of the culprit lesion only with staged PCI to non- culprit lesions within 2 weeks, and group II which included 50 cases who were subjected to PCI of all diseased vessels eligible for PCI.

Regarding age, gender, diabetes, smoking, dyslipidemia \& family history of IHD there was no significant differences between group I $\&$ group II in our study \& in another studies $(12 \& 14)$.

In our study, the total procedure time was significantly prolonged in group II ( $\mathrm{p}<0.001)$. It had a mean value of 46 and 71 minutes in both groups respectively. However, there was a significant increase in the contrast volume in group I $(\mathrm{p}<0.001)$.

In another study, the mean PCI time was significantly longer in patients assigned to total revascularization versus in those who had culprit only PCI. This agrees with our findings (16). However, larger volume of contrast material was needed in total revascularization patients compared to culprit only PCI patients in the same study. This contradicts with our results.

As regard TIMI flow in the current study, it was significantly different between the two groups before intervention $(\mathrm{p}=0.005)$. Score 1 was the commonest score in group I (46\%), whereas score 3 was the commonest in group II (44\%). As well as another study reported that there was significant difference between the 
two groups regarding pre-intervention TIMI flow grade $(\mathrm{p}<0.001)$. Grade 3 was present in $53.7 \%$ and $63.5 \%$ of cases in 1-stage and multi-stage groups respectively (14).

After intervention in our study, a significant improvement of TIMI flow was detected in both groups. Score 3 was present in 92 and $94 \%$ of cases in both groups respectively.

Another study reported that the procedural success was ad In the current study, the number of stents used was signafidabloy dfferent

Regarding complications encountered in the current study, coronary dissection was encountered in 6 and $4 \%$ of cases in both groups $(\mathrm{p}=1)$. Other complications like major bleeding was not encountered in our study. When it comes to other in-hospital complications in our study, there was no significant difference between the two groups regarding cardiogenic shock, heart failure, or contrast induced nephropathy $(\mathrm{p}>0.05)$.

Another study reported that arterial complications were encountered more significantly after 1-stage procedure (0.6 vs. $0.4 \%$ of cases $-\mathrm{p}=0.008)$. However, bleeding complications did not differ between the two groups in that study (14).

Engstrøm and his colleagues also reported that there was no significant difference between the two groups regarding post-procedure complications (bleeding or contrast induced nephropathy) (p > 0.05) (12).

As regard in-hospital mortality in our study, it was not significantly different between the two groups. However, in-hospital mortality was encountered in $2 \%$ of cases in group II, while it was absent in group I. On 6-month follow up in the current study, heart failure was encountered in 2 cases in each group $(\mathrm{p}=1)$. Moreover, recurrent anginal pain was experienced in 4 cause mortality, need for urgent TVR, and nonfatal MI were not experienced during that follow up period.

In a large registry study, the clinical outcome of patients with STEMI was compared between individuals who had PCI of the culprit lesion only during the index procedure, those who had complete revascularization before discharge, or people who had staged revascularization of additional lesions in non-infarct-related arteries within 2 months of the index treatment. Lower in-hospital mortality was found in the group treated for the culprit lesion only, whereas long-term mortality was lowest for patients who had complete revascularization within 2 months (18).

In another recent study, multiple vessel revascularization (MVR) reduced 2-year adverse cardiac events in patients with NSTEMI and MVD compared to culprit vessel 
revascularization. However, staged revascularization was not superior to one-time revascularization for reducing MACE among NSTEMI patients with MVD who received MVR (19).

\section{Conclusion}

Immediate complete revascularization resulted in similar rates of in-hospital and 6-month outcomes compared to staged revascularization. Further large prospective randomized trials are needed to definitively answer this important clinical question.

\section{References}

(1) Fuster V, Moreno PR, Fayad ZA, Corti R, Badimon JJ. Atherothrombosis and high-risk plaque: part I: evolving concepts. Journal of the American College of Cardiology. 2005 Sep 20;46(6):937-54.

(2) Shishehbor MH, Topol EJ, Mukherjee D, Hu T, Cohen DJ, Stone GW, et al TARGET Investigators. Outcome of multivessel coronary intervention in the contemporary percutaneous revascularization era. The American journal of cardiology. 2006 Jun 1;97(11):1585-90.

(3) Rasoul S, Ottervanger JP, de Boer MJ, Miedema K, Hoorntje JC, Gosselink M, et al. A comparison of dual vs. triple antiplatelet therapy in patients with non-ST-segment elevation acute coronary syndrome: results of the ELISA-2 trial.
European heart journal. 2006 Jun 1;27(12):1401-7.

(4) Jaski BE, Cohen JD, Trausch J, Marsh DG, Bail GR, Overlie PA, et al. Outcome of urgent percutaneous transluminal coronary angioplasty in acute myocardial infarction: comparison of singlevessel versus multivessel coronary artery disease. American heart journal. 1992 Dec 1;124(6):142733.

(5) Lagerqvist B, Husted S, Kontny F, Ståhle E, Swahn E, Wallentin L, Fast Revascularisation during InStability in Coronary artery disease (FRISC-II) Investigators. 5-year outcomes in the FRISC-II randomised trial of an invasive versus a non-invasive strategy in non-ST-elevation acute coronary syndrome: a follow-up study. The Lancet. 2006 Sep 16;368(9540):998-1004.

(6) Virmani R, Burke AP, Farb A, Kolodgie FD. Pathology of the vulnerable plaque. Journal of the American College of Cardiology. 2006 Apr 18;47(8 Supplement):C13-8.

(7) Vergallo R, Ren X, Yonetsu T, Kato K, Uemura $\mathrm{S}, \mathrm{Yu} \mathrm{B}$, et al. Pancoronary plaque vulnerability in patients with acute coronary syndrome and ruptured culprit plaque: a 3-vessel optical coherence tomography study. American heart journal. 2014 Jan 1;167(1):59-67.

(8) Rosengren A, Wallentin L, Gitt AK, Behar S, Battler A, Hasdai D. Sex, age, and clinical presentation of acute coronary syndromes. European Heart Journal. 2004 Apr 1;25(8):663-70.

(9) Bajratari G, Henein MY. Treatment strategies of NSTEMI-ACS with multivessel disease. 
International Cardiovascular Forum Journal. 2016;6:3-5. DOI: 10.17987/icfj.v6i0.211.

(10) Wald DS, Morris JK, Wald NJ, Chase AJ, Edwards RJ, Hughes LO, et al. Randomized trial of preventive angioplasty in myocardial infarction. $\mathrm{N}$ Engl J Med. 2013 Sep 19;369:1115-23.

(11) Gershlick AH, Khan JN, Kelly DJ, Greenwood JP, Sasikaran T, Curzen N, et al. Randomized trial of complete versus lesion-only revascularization in patients undergoing primary percutaneous coronary intervention for STEMI and multivessel disease: the CvLPRIT trial. Journal of the American College of Cardiology. 2015 Mar 17;65(10):963-72.

(12) Engstrøm T, Kelbæk H, Helqvist S, Høfsten DE, Kløvgaard L, Holmvang L, et al. Complete revascularisation versus treatment of the culprit lesion only in patients with ST-segment elevation myocardial infarction and multivessel disease (DANAMI-3-PRIMULTI): an open-label, randomised controlled trial. The Lancet. 2015 Aug 15;386(9994):665-71.

(13) Roffi M, Patrono C, Collet JP, Mueller C, Valgimigli M, Andreotti F, et al . 2015 ESC Guidelines for the management of acute coronary syndromes in patients presenting without persistent ST-segment elevation: Task Force for the Management of Acute Coronary Syndromes in Patients Presenting without Persistent ST-Segment Elevation of the European Society of Cardiology (ESC). European heart journal. 2016 Jan 14;37(3):267-315.

(14) Rathod KS, Koganti S, Jain AK, Astroulakis
Z, Lim P, Rakhit R, et al. Complete versus culpritonly lesion intervention in patients with acute coronary syndromes. Journal of the American College of Cardiology. 2018 Oct 23;72(17):198999.

(15) Pijls NH, Fearon WF, Tonino PA, Siebert U, Ikeno F, Bornschein B, et al. Fractional flow reserve versus angiography for guiding percutaneous coronary intervention in patients with multivessel coronary artery disease: 2-year followup of the FAME (Fractional Flow Reserve Versus Angiography for Multivessel Evaluation) study. Journal of the American College of Cardiology. 2010 Jul 13;56(3):177-84.

(16) Salem M, Farag S, Atia AI, Seleem M, Mansour H. Multivessel Stenting versus CulpritOnly Stenting in Multivessel Coronary Artery Disease Patients Presented with Non-ST-Segment Elevation Acute Coronary Syndrome (NSTE-ACS). J Cardiol Curr Res. 2015;3(6):00122.

(17) Shishehbor MH, Lauer MS, Singh IM, Chew DP, Karha J, Brener SJ, et al. In unstable angina or non-ST-segment acute coronary syndrome, should patients with multivessel coronary artery disease undergo multivessel or culprit-only stenting?. Journal of the American College of Cardiology. 2007 Feb 27;49(8):849-54.

(18) Hannan EL, Samadashvili Z, Walford G, Holmes DR, Jacobs AK, Stamato NJ, et al. Culprit vessel percutaneous coronary intervention versus multivessel and staged percutaneous coronary intervention for ST-segment elevation myocardial infarction patients with multivessel disease. JACC: 
Cardiovascular Interventions. 2010 Jan 1;3(1):2231.

(19) Kim M, Ahn Y, Jeong MH, Sim DS, Hong YJ, Kim JH, et al. P3127 Optimal revascularization strategy in non-ST-segment elevation myocardial infarction with multivessel coronary artery disease: staged vs. one-time vs. culprit-only

To cite this article: Mohammed H. Kabil, Ahmed Bendary, Mohamed A. Salem, Khaled E. El Rabbat. Complete versus Staged Revascularization in Patients with Non-ST Segment Elevation Acute Coronary Syndrome (NSTE-ACS) and Multivessel Disease. BMFJ 2021;38(2):430-442. DOI: $10.21608 / \mathrm{bmfj} .2020 .26522 .1234$ 